\title{
APLIKASI KEBIJAKAN JAMINAN KESEHATAN DI JATINANGOR
}

\author{
Oleh: \\ Muhammad Fahmi Amrullah, Moch Zainuddin \& Muhammad Fedryansyah
}

Email:

(fahmimahameru@gmail.com; moch.zainuddin57@gmail.com; fedry_cons@yahoo.com)

\begin{abstract}
ABSTRAK
Jatinangor merupakan salah satu kecamatan yang berada di Kabupaten Sumedang. Melihat kondisi kecamatan Jatinangor yang semakin maju di bidang pendidikan, ekonomi, ketenagakerjaan, dan kesehatan, tidak dapat dipungkiri permasalahan-permasalahan yang ada pun semakin kompleks sebagai dampak dari kemajuan tersebut. Khusus dalam bidang kesehatan, pemerintah Kabupaten Sumedang mempunyai program Jaminan Kesehatan Semesta (JAMKESTA) dan program Jaminan Kesehatan Daerah (JAMKESDA). Jamkesda merupakan salah satu bentuk perlindungan sosial dibidang kesehatan untuk menjamin akses untuk masyarakat terhadap pelayanan kesehatan yang layak dan menyeluruh yang dilaksanakan oleh daerah. Melihat RPJMD Kabupaten Sumedang tentang implementasi program Jaminan Kesehatan Daerah (JAMKESDA) maka dalam mengaplikasikan kebijakan, semua orang harus ikut serta mengawasi dimulai dari proses formulasi kebijakan sampai dengan proses implementasi kebijakan di masyarakat. Hal ini sangat penting jika kebijakan sosial mampu di terapkan dengan baik maka tujuan dari kebijakan tersebut dapat tercapai. Proses pembentukan kebijakan ini meliputi political sphere, administrative sphere, dan operational sphere. Oleh sebab itujika kebijakan jaminan kesehatan ini mampu di implementasikan dengan baik maka tujuan dari kebijakan tersebut dapat tercapai.
\end{abstract}

Kata kunci: Kesehatan, jaminan kesehatan, dan formulasi kebijakan

\section{PENDAHULUAN}

Jatinangor merupakan salah satu kecamatan yang berada di Kabupaten Sumedang. Melihat kondisi kecamatan Jatinangor yang semakin maju di bidang pendidikan, pertumbuhan ekonomi, ketenagakerjaan, kesehatan dan lain-lain, begitu pula pertumbuhan permasalahan-permasalahan yang juga semakin kompleks. Khusus dalam bidang kesehatan pemerintah Kabupaten Sumedang mempunyai program Jaminan Kesehatan Semesta (JAMKESTA) dan program Jaminan Kesehatan Daerah (JAMKESDA).

Jaminan kesehatan Semesta (Jamkesta), yaitu jaminan kesehatan bagi seluruh lapisan masyarakat atau bagi seluruh penduduk Sumedang akan dimulai pada 2014.Saat ini, masyarakat Sumedang yang terlindungi asuransi kesehatan hanya 30 persen. Itupun ada yang disubsidi pemerintah ada yang tidak, seperti askes, jamkesmas, jamkesda, dan jamsostek, serta asuransi kesehatan lainnya.

Saat ini sekitar 63,5 persen penduduk Indonesia atau 151,5 juta jiwa telah mempunyai jaminan kesehatan dengan berbagai cara penjaminan. Itu termasuk para peserta Jamkesmas, Jamkesda, Askes, PNS Pensiunan dan Veteran, TNI POLRI aktif, Jamsostek, jaminan oleh perusahaan dan individu peserta jaminan kesehatan dari perusahaan asuransi kesehatan swasta. Artinya, masih terdapat 37 persen penduduk atau 87 juta jiwa yang belum tercakup dalam jaminan kesehatan. 
Setiap pemerintah daerah baik provinsi dan kabupaten atau kota wajib menyusun suatu perencanaan pembangunan daerah. Berupa RPJPD (Rencana Pembangunan Jangka Panjang Daerah) untuk kurun waktu perencanaan 20 tahun, RPJMD (Rencana Pembangunan Jangka Menengah Daerah) untuk kurun waktu perencanaan 5 tahun dan, RKPD (Rencana Kerja Pembangunan Daerah) untuk kurun waktu perencanaan 1 tahun.

Rencana Pembangunan Jangka Menengah Daerah (RPJMD) Kabupaten Sumedang Tahun 20092013 adalah bentuk perencanaan daerah untuk periode 5 tahunan yang merupakan penjabaran dari visi, misi dan program Kepala Daerah berdasarkan kepada Rencana Pembangunan Jangka Panjang Daerah (RPJP) serta memperhatikan RPJM Nasional dan RPJMD Provinsi Jawa Barat. Melihat RPJMD Kabupaten Sumedang tentang implementasi program Jaminan Kesehatan Daerah (JAMKESDA).

\section{PEMBAHASAN \\ Jaminan Kesehatan Daerah}

Jaminan Kesehatan Daerah atau Jamkesda adalah bentuk perlindungan di bidang sosial, dalam Peraturan Daerah Kab. Sumedang No. 7 Tahun 2010, apa yang dimaksud dengan Jamkesda adalah salah satu bentuk perlindungan sosial dibidang kesehatan untuk menjamin akses untuk masyarakat terhadap pelayanan kesehatan yang layak dan menyeluruh yang dilaksanakan oleh daerah.

Menurut konsep diatas pada dasarnya kesehatan adalah hal yang sangat penting bagi masyarakat Indonesia. Sehingga dibuatlah sistem perlindungan kesehatan bagi masyarakat Indonesia. Terbentuknya masyarakat Indonesia yang sehat akan berdampak pula pada aspek-aspek lainnya.

Oleh karena itu maksud dan tujuan diselenggarakannya Jamkesda adalah sebagai landasan awal untuk melaksanakan program dan aktivitas penyelenggaraan pembangunan kesehatan yang dilaksanakan oleh pemerintah daerah, melaui upaya pemberian jaminan kesehatan kepada masyarakat Indonesia dan pembiayaannya dikelola secara mandiri, terkoordinasi, partisipatif, transparan, dan akuntabel.

Terselenggaranya jaminan kesehatan oleh pihak masyarakat, swasta maupun pemerintah secara sinergis, sehingga tercapai kesehatan masyarakat yang setinggi-tingginya meliputi :

1. Pemberian jaminan kesehatan kepada seluruh peserta

2. Pemberian kemudahan terhadap keterjangkauan pelayanan kesehatan kepada seluruh peserta

3. Peningkatan pelayanan kesehatan yang tersetandar bagi peserta

4. Penyelenggaraan pengelolaan keuangan yang transparan dan akuntabel

Setiap penduduk kabupaten sumedang wajib menjadi anggota Jamkesda. Peserta wajib terdaftar dengan diberikan kartu identifikasi peserta. Pengaturan kepesertaan diatur lebih lanjut oleh peraturan Bupati.

\section{Kebijakan Sosial}

Dalam buku "Social Policy in The Post-Welfare State - Adam Jamrozik" kebijakan sosial memiliki pengertian :

Social policy is concerned with the regulation of social relationships for the purpose of affirming certain values and interest through the implementation of appropriate means designed to achieve corresponding ends (Gil 1976).

Terkait pengertian "through the implementation of appropriate means" jika kebijakan sosial mampu di terapkan dengan baik maka tujuan dari kebijakan tersebut dapat tercapai.(Jamrozik,1992) Kebijakan di bagi menjadi 3 (tiga) tahap. Tahapan pertama yaitu Political Sphere (policy formulation). Tahapan ini yaitu dimana setiap aturan yang dibuat pemerintahan baik undang-undang sampai dengan peraturan daerah di terjemahkan kedalam sebuah kebijakan. Selanjutnya adalah 
tahapan Administrative Sphere. Dalam tahap ini, semua bentuk birokrasi pemerintah dan non pemerintah menginterpretasikan kebijakan menjadi sebuah program-program. Menurut Jamrozik untuk menginterpretasikan kebijakan ini mampu dilakukan oleh "one of government department or non-government sector.

Jamrozik menyebutkan dalam tahapan ini sebagai regulator, dalam hal ini yaitu Dinas Kesehatan Kabupaten Sumedang as the govrnment department. Tahapan selanjutnya adalah Operational Sphere. Dalam tahapan ini produk dari kebijakan yaitu program-program diimplementasikan (policy application). Pelaksanaan program Jamkesda dalam hal ini yaitu puskesmas sebagai implementor.

Akhir-akhir ini penyelenggaraan jaminan kesehatan sering terdengar berita sulitnya masyarakat Indonesia untuk mendapatkan pelayanan jaminan kesehatan. Misalnya penyelenggaraan Jaminan Kesehatan Daerah. Banyaknya masyarakat yang masih sulit mendapatkan perlindungan atau jaminan keehatan menjadi alasan utama, apakah program jaminan kesehatan daerah sudah sesuai dengan proses formulasi kebijakan kesehatan. Apakah permasalahan ini diakibatkan kesalahan formulasi kebijakan, yang mana tahap formulasi kebijakan ada tiga yaitu Political Sphere, Administrative Sphere, dan Operational Sphere (Jamrozik, 1992). Oleh karena itu dalam mengaplikasikan kebijakan harus diawasi penuh oleh berbagai pihak agar implementasi program yang sudah di rancang yaitu Jaminan Kesehatan Daerah bisa terlaksana dengan baik.

\section{PENUTUP}

Kesehatan adalah hal yang sangat penting bagi masyarakat Indonesia, sebagai salah satu bentuk perlindungan sosial dibidang kesehatan, untuk menjamin akses bagi masyarakat terhadap pelayanan kesehatan yang layak dan menyeluruh yang dilaksanakan oleh pemerintah daerah. Oleh karena itu maksud dan tujuan diselenggarakannya Jamkesda adalah sebagai landasan awal untuk melaksanakan program dan aktivitas penyelenggaraan pembangunan kesehatan, melaui upaya pemberian jaminan kesehatan kepada masyarakat Indonesia dan pembiayaannya dikelola secara mandiri, terkoordinasi, partisipatif, transparan, dan akuntabel.

Fasilitas kesehatan harus semakin ditingkatkan, dan fasilitas kesehatan yang sangat dekat dengan masyarakat yaitu puskesmas dan klinik seharusnya bisa melayani pendaftaran peserta Jaminan Kesehatan Daerah. Oleh sebab itujika kebijakan jaminan kesehatan ini mampu di implementasikan dengan baik maka tujuan dari kebijakan tersebut dapat tercapai.

\section{DAFTAR PUSTAKA}

Colby, Ira.C. 2008. Social Work and Social Welfare - Social Policy and Policy Practice.USA. John Wiley \& Sons, Inc.

PUSDATIN, Kesos.2009.“GLOSARIUM-Penyelenggaraan Kesejahteraan Sosial. Jakarta. Departemen Sosial Republik Indonesia

Zamrozik, A. (2009). Social Policy In The Post-Welfare State. australia.

Zastrow, Charles.1994."The Practice of Social Work - 5th Edition”.California. Brooks/Cole Publishing Company 